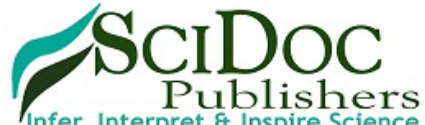

\author{
International Journal of Dentistry and Oral Science (IJDOS) \\ ISSN: 2377-8075
}

\title{
Prevalence of Class II Division 2 Malocclusion and Its Associated Factors - A Retrospective Study in A Private Dental Hospital In Chennai, Tamilnadu
}

Research Article

\author{
Janhvi Manohar ${ }^{1 *}$, Srirengalakshmi² S.P. Saravana Dinesh ${ }^{3}$ \\ ${ }^{1}$ Saveetha Dental College and Hospitals, Saveetha Institute of Medical and Technical Sciences, Saveetha University, Chennai-77, India. \\ ${ }^{2}$ Senior Lecturer, Department of Orthodontics, Saveetha Dental College and Hospitals, Saveetha Institute of Medical and Technical sciences, \\ Saveetha University, Chennai-77, India. \\ ${ }^{3}$ Professor and Admin Head, Department of Orthodontics, Saveetha Dental College, Saveetha Institute of Medical and Technical Sciences, Saveetha \\ University, Chennai-77, India.
}

Abstract

\begin{abstract}
Malocclusion is defined as the improper relationship of maxillary to mandibular teeth. Prevalence of the various types of malocclusion vary among different genders, races, ethnicities. Generally, genetics play a very important role in contributing to the same. Class II division 2 malocclusion is one of the lesser common types of malocclusion found in the population. The aim of our study is to analyse the association of class II division 2 malocclusion with gender, age groups and most commonly associated inter-arch and intra-arch malocclusions in the city of Chennai, a study performed in a private dental hospital. A retrospective analysis was done wherein patients' intraoral photographs were checked for cross reference and Chi-square tests were performed. 108 patients were observed with Class II division 2 malocclusion out of which $58.3 \%$ were males and $41.7 \%$ were females. A higher prevalence of Class II division 2 malocclusion among males ( $\mathrm{p}$ value $>0.05$ ) was observed and patients of age group 21-30 years were most commonly encountered in the clinic with Class II division 2 malocclusion ( $\mathrm{p}$ value $>0.05$ ). Scissor bite ( $\mathrm{p}$ value $>0.05$ ) was most commonly found as an associated malocclusion trait among these patients.
\end{abstract}

Keywords: Malocclusion; Angle’s Classification; Class II Malocclusion; Class II Division 2.

\section{Introduction}

Malocclusion can be defined as the improper relationship between maxillary and mandibular teeth or as deviations of teeth and jaws from normal alignment [1]. Orthodontic treatment is based on the principle that if prolonged pressure is applied to a tooth, tooth movement will occur as the bone around the tooth remodels [2]. Malocclusion can be due to discrepancies of tooth and jaw size, mal-relationships between dental arches in the sagittal, transverse and vertical positions, or it may also be due to malpositioning of individual teeth. Studies have been done stating that the gonial angle can also predict the growth pattern [3]. Angle's classification is a universally accepted classification used to define the relationship of the maxillary first molar with the mandibular first molar due to its simplicity and the ease of communication between dental professionals.
Class II malocclusion are described as a distal relationship of the mandibular first molar to the maxillary first molar. Class II malocclusion has two divisions and one subdivision The class II division 2 malocclusion, which is of current importance, is defined as the class II malocclusion with lingual inclination of the maxillary central incisors, a deep cite and minimal overjet. The Class II malocclusions occurring unilaterally are depicted or classified as a Class II subdivision of the affected side. It is also seen in some congenital syndromes such as Brodie syndrome, Pierre Robin syndrome, Treacher Collin syndrome, Mobius syndrome.

Class II division 2 malocclusion is usually frequently occurring more in males than females as reported by Srdharan et al., [4] The difficulty in studying the prevalence lies in identifying and interpreting the class II division 2 malocclusions due to different methods and techniques used in other studies dealing with different ethnicities or races.

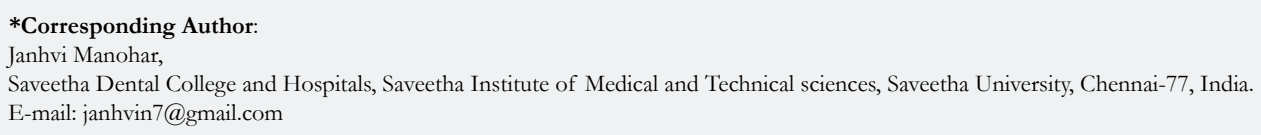

Copyright: Janhvi Manohar 2019. This is an open-access article distributed under the terms of the Creative Commons Attribution License, which permits unrestricted use, distribution and reproduction in any medium, provided the original author and source are credited. 
Studies regarding the prevalence of class II malocclusions have observed a greater prevalence in white population than the black people [5]. It was observed that a class II malocclusion, may be accompanied by an antero-posterior skeletal discrepancy between the maxilla and the mandible, either in the form of a retruded mandible or a protruded maxilla. These relationships are superimposed or a broad variation in the vertical face pattern that ranges between increased, normal or decreased total and lower facial heights [6]. Investigating the prevalence will help understand the diversity occurring traits and variations and guide us in the assessment of orthodontic treatment.

India being a large country consists of populations from multiple ethnicities, namely seven among which Dravidians are one of subethnic groups inhabiting South India and this study is based on the same [7]. There has been a range of $0.6 \%$ to $6.7 \%$ of the population being diagnosed as a class II division 2 malocclusion as estimated from the studies done all over the world. Different regions seemed to have somewhat a similar prevalence with varying occlusal traits. Good documentation of the variations found among the population and estimating prevalence will aid in identifying an association, if any, and will lead to an efficient progression of the orthodontic services being delivered, better treatment planning and execution. Studies have been done in our university on mini-implants used for anchorage [8-11], tested efficiency of different orthodontic bonding adhesives $[12,13]$, analysed different methods of recycling brackets [14], the ill-effects of obstructive sleep apnea on dentition [15], clinical reports [16, 17], effects of bisphosphonates on orthodontic tooth movement [18] and performed angular photogrammetric analysis of Indian adults [19] but there are not sufficient epidemiological studies with the data present, this study hopes to do the same. The aim of the study is to analyse the association of class II division 2 malocclusion with gender, age groups and most commonly associated inter-arch and intra-arch malocclusions.

\section{Materials and Methods}

A retrospective study was carried out in a university setting among patients visiting the dental hospital, a predominantly south Indian population was chosen for the study. A total of 8967 records of patients who visited a private dental hospital for treatment of malocclusion were analysed and checked for class II division 2 malocclusion.

\section{Selection of Subjects}

The case sheets of patients of 18 to 60 years who reported to the clinic and were observed to have Class II division 2 malocclusion were collected from the time period from June 2019 to March 2020 .

\section{Data collection}

Records of the patients were obtained from the outpatient department of a private dental college. Cross verification was done by reviewing the intraoral photographs and checking for retruded maxillary incisors and decreased overjet. Approval for the study and permission to access patients' records was obtained from the ethical review Board of Saveetha Institute of Medical and Technical Sciences with the approval number: SDC/SIHEC/2020/

\section{DIASDATA/0619-0320}

\section{Inclusion criteria:}

\author{
- Patients of age 18 to 40 years \\ - Permanent dentition (no retained deciduous teeth)
}

\section{Exclusion criteria:}

- Patients with congenital syndromes causing facial asymmetry

- Patients with systemic diseases

- Patients with history of orthodontic treatment done

- Patients who have undergone extractions of teeth other than third molars

Incomplete data was excluded due to the possibility of bias.

\section{Statistical analysis}

The data about patients' age, gender and inter-arch relation was collected and tabulated and subjected to statistical analysis. Using SPSS software, descriptive statistics and Chi square tests were performed.

\section{Results and Discussion}

The study included 8967 patients out of which 108 patients were observed to have Class II division 2 malocclusion. The prevalence of Class II division 2 was calculated at $1.2 \%$ out of which 62 were males and 46 were females. We observed that males were most characterised as having Class II division 2 malocclusion $(\mathrm{p}>0.05)$ as seen in Figures 1, 3. The most common associated malocclusion observed was scissor bite $(\mathrm{p}>0.05)$ seen greatly among men as seen in Figures 4, 5. A greater number of patients within the age group of 21-30 years reported to the dental clinic with Class II division 2 malocclusion among which scissor bite was majorly observed among the same age group as seen in Figures 2,6.

The present research was undertaken for exploring the prevalence of Angles Class II division 2 malocclusion, providing information about the occlusal variation among patients visiting Saveetha Dental College and Hospitals and comparing this analysis with other world populations. The age of the subjects in the sample studied ranged from 18 to 40 years. This age range was a criterion for two reasons being, first; reliable assessment of the occlusion and establishing a classification should be done on permanent dentition. As any variations that are present at the mixed dentition stage, will modify the occlusion and thus the classification, second; the reliable estimation of occlusal status should be done post cessation of craniofacial growth and development.

The Chi-square association among the gender of the patients and the ages of the patients with Angles Class II division 2 malocclusion, $(p>0.05)$ - non significant, however the male population was observed to be predominant as shown by Figure 1. The occlusal variations or the prevalence of Angles Class II division 2 malocclusion varied among genders, thus, it can be said that occlusal variation is not independent of gender.

This association matched with the results observed by Sridharan $\mathrm{K}$ et al., [4] who stated a $0.4 \%$ prevalence in females and a $0.8 \%$ 
Figure 1. Bar graph representing gender-wise distribution of Class II division 2 malocclusion. $X$ axis represents gender of patients and $\mathrm{Y}$ axis represents the total number of patients in that category. Higher prevalence of Class II division 2 malocclusion was observed in males (blue).

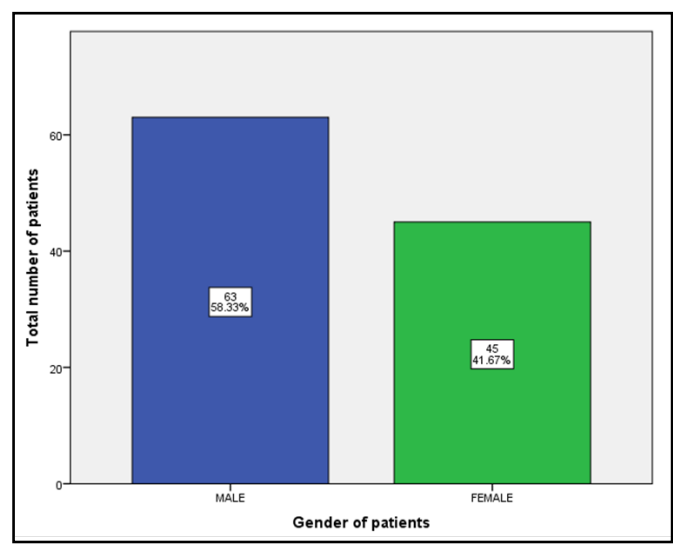

Figure 2. Bar graph representing age-wise distribution of Class II division 2 malocclusion. $X$ axis represents age groups of patients and $\mathrm{Y}$ axis represents the total number of patients in that category. Higher prevalence of Class II division 2 malocclusion was in patients in the age group 21-30 years (red).

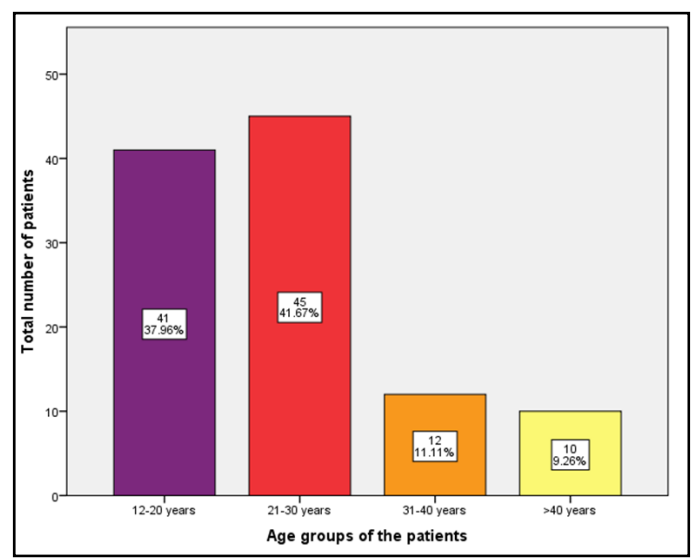

Figure 3. Bar graph representing frequency distribution between age and gender of patients with Class II division 2 malocclusion. $\mathrm{X}$ axis denotes the age group of patients and $\mathrm{Y}$ axis represents total number of patients in each category. ChiSquare test, p value: 0.489 (>0.05), statistically non-significant. Males (blue) with Class II division 2 were of the age group 21-30 years and most females (green) were below 20 years.

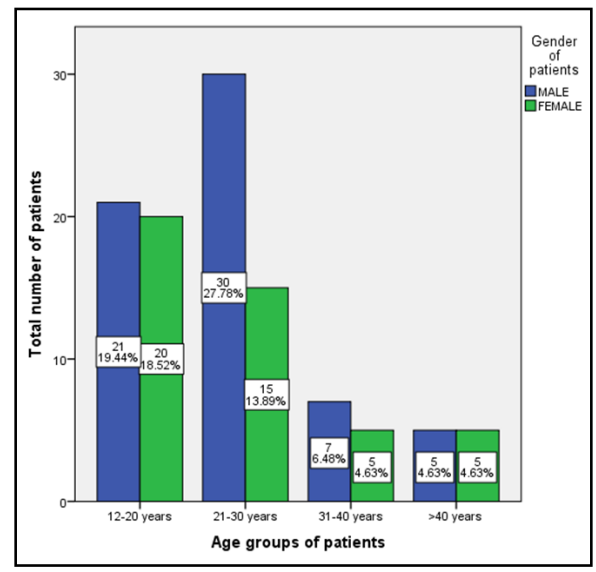

prevalence of Angles Class II division 2 malocclusion among males. This observation showed a 1:2 prevalence among females and males. However, a contradicting analysis was made by Aslam A stating a female predominance in the prevalence of Angles Class II division 2 malocclusion. However, this cannot be taken into account as the study done by Aslam A et al., included patients from the age of 8 years. Our study also correlated with the study done on Dane population [20]. However, it must be clearly stated that the occlusal variation among this group of population differs numerically from other studies in various other parts of the world. These variations can be attributed to the genetic background, diverse criteria and subjective examiner disparities [21, 22].

Figure 2 shows the associated malocclusion among the patients with Angles class II division 2 malocclusion. It was observed from our study that the majority of the population did not have any associated malocclusion (65\%) followed by patients having a scissor bite. This observation was supported by studies done by 
Figure 4. Bar graph representing frequency distribution of the associated malocclusions observed in Class II division 2 malocclusion. $\mathrm{X}$ axis represents associated malocclusions and $\mathrm{Y}$ axis represents the total number of patients in that category. Scissor bite (light blue) was the most common inter-arch relation observed in Class II division 2 patients.

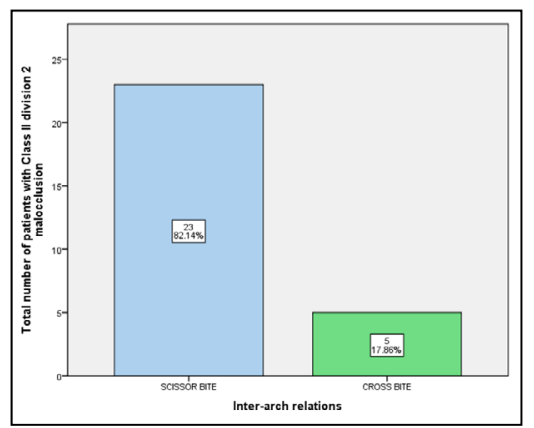

Figure 5. Bar graph representing correlation between inter-arch relation and gender of patients with Class II division 2 malocclusion. $X$ axis denotes the inter-arch relation and $Y$ axis represents total number of patients in each category. ChiSquare test, p value: $0.581(>0.05)$, hence statistically non-significant but a trend is observed in the direction that scissor-bite was the most commonly observed associated malocclusion among males (blue) with Class II division 2 malocclusion.

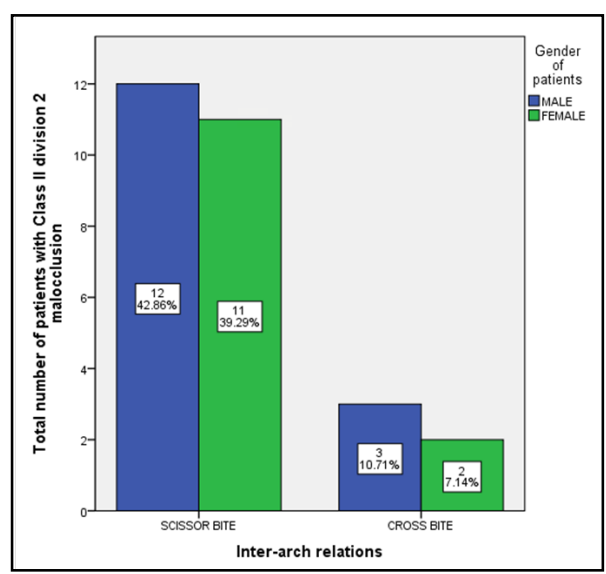

Figure 6. Bar graph representing association between inter-arch relation and age groups of patients with Class II division 2 malocclusion. $\mathrm{X}$ axis denotes the inter-arch relation and $\mathrm{Y}$ axis denotes the total number of patients in that category. Chisquare test, $p$ value: $0.097(>0.05)$, hence statistically non significant but a trend is observed in the direction that patients less than 20 years (violet) were highly observed to have scissor-bite in a clinical setup.

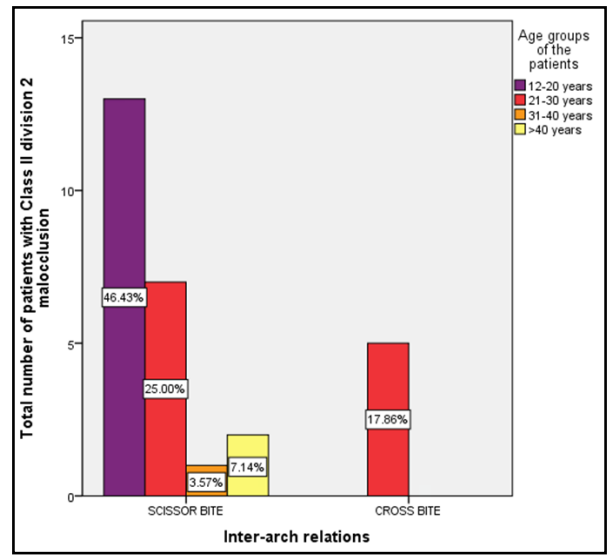

Walkow et al, 2002 [23] and Enlow et al, 1996 [24]. Scissor bite was observed to be most commonly observed in younger patients.

The limitations of the study are that it covers only one metropolitan area and the limited sample size. However, the study of prevalence of a certain type of malocclusion will help analyse the gender wise and race wise distribution of the different malocclusions.

\section{Acknowledgement and Declarations}

I would like to thank the Chancellor, Director of academics and the Dean of Saveetha Dental College for the constant encouragement with my work during all stages of the study. Approval for the study and permission to access patients' records was obtained from the ethical review Board of Saveetha Institute of Medical and Technical Sciences with the approval number: SDC/ SIHEC/2020/DIASDATA/0619-0320 


\section{Conclusion}

From the study done, it can be concluded that, within the limits of our study, higher prevalence of class II division 2 malocclusion among males was observed and scissor bite was reported as the most commonly observed associated malocclusion trait in Class II division 2 patients. Patients of age group 21-30 years were most commonly encountered in the clinic with Class II division 2 malocclusion. Further studies with a larger population can help us estimate the prevalence based on race and therefore incorporate better and paves way for more efficient treatment planning.

\section{References}

[1]. Mtaya M, Brudvik P, Astrøm AN. Prevalence of malocclusion and its relationship with socio-demographic factors, dental caries, and oral hygiene in 12- to 14-year-old Tanzanian schoolchildren. Eur J Orthod. 2009 Oct;31(5):467-76.Pubmed PMID: 19336630.

[2]. Viswanath A, Ramamurthy J, Dinesh SP, Srinivas A. Obstructive sleep apnea: awakening the hidden truth. Niger J Clin Pract. 2015 Jan-Feb;18(1):1-7. Pubmed PMID: 25511335

[3]. Rubika J, Felicita AS, Sivambiga V. Gonial angle as an indicator for the prediction of growth pattern. World J Dent. 2015;6(3):161-3.

[4]. Felicita AS, Chandrasekar S, Shanthasundari KK. Determination of craniofacial relation among the subethnic Indian population: a modified approach - (Sagittal relation). Indian J Dent Res. 2012 May-Jun;23(3):305-12. Pubmed PMID: 23059564.

[5]. Klages U, Bruckner A, Zentner A. Dental aesthetics, self-awareness, and oral health-related quality of life in young adults. Eur J Orthod. 2004 Oct;26(5):507-14.Pubmed PMID: 15536839.

[6]. Shivakumar KM, Chandu GN, Subba Reddy VV, Shafiulla MD. Prevalence of malocclusion and orthodontic treatment needs among middle and high school children of Davangere city, India by using Dental Aesthetic Index. J Indian Soc Pedod Prev Dent. 2009 Oct-Dec;27(4):211-8.Pubmed PMID: 19915271.

[7]. McLain JB, Proffitt WR. Oral health status in the United States: prevalence of malocclusion. J Dent Educ. 1985 Jun;49(6):386-97.Pubmed PMID: 3859517.

[8]. Jonsson T, Arnlaugsson S, Karlsson KO, Ragnarsson B, Arnarson EO, Magnusson TE. Orthodontic treatment experience and prevalence of malocclusion traits in an Icelandic adult population. Am J Orthod Dentofacial Orthop. 2007 Jan;131(1):8.e11-8.Pubmed PMID: 17208100.

[9]. Samantha C, Sundari S, Chandrasekhar S, Sivamurty G, Dinesh S. Comparative Evaluation of Two Bis-GMA Based Orthodontic Bonding Adhesives - A Randomized Clinical Trial. J Clin Diagn Res. 2017 Apr;11(4):ZC40ZC44.Pubmed PMID: 28571259.

[10]. Krishnan S, Pandian S, Kumar S A. Effect of bisphosphonates on orthodontic tooth movement-an update. J Clin Diagn Res. 2015 Apr;9(4):ZE01-5. Pubmed PMID: 26023659.

[11]. Kamisetty SK, Verma JK, Arun, Sundari S, Chandrasekhar S, Kumar A. SBS vs Inhouse Recycling Methods-An Invitro Evaluation. J Clin Diagn Res. 2015 Sep;9(9):ZC04-8.Pubmed PMID: 26501002.

[12]. Heikinheimo K, Nyström M, Heikinheimo T, Pirttiniemi P, Pirinen S. Dental arch width, overbite, and overjet in a Finnish population with normal occlusion between the ages of 7 and 32 years. Eur J Orthod. 2012 Aug;34(4):418-26.Pubmed PMID: 21357654.

[13]. Krooks L, Pirttiniemi P, Kanavakis G, Lähdesmäki R. Prevalence of malocclusion traits and orthodontic treatment in a Finnish adult population. Acta Odontol Scand. 2016 Jul;74(5):362-7.Pubmed PMID: 26940248.

[14]. Staley RN. Etiology and prevalence of malocclusion. Textbook of orthodontics. 2001;83-96.

[15]. Mahesh Kumar P, Joseph T, Varma RB, Jayanthi M. Oral health status of
5 years and 12 years school going children in Chennai city--an epidemiological study. J Indian Soc Pedod Prev Dent. 2005 Mar;23(1):17-22.Pubmed PMID: 15858301.

[16]. Ramesh Kumar KR, Shanta Sundari KK, Venkatesan A, Chandrasekar S. Depth of resin penetration into enamel with 3 types of enamel conditioning methods: a confocal microscopic study. Am J Orthod Dentofacial Orthop. 2011 Oct;140(4):479-85.Pubmed PMID: 21967934.

[17]. Soh J, Sandham A. Orthodontic treatment need in Asian adult males. Angle Orthod. 2004 Dec;74(6):769-73.Pubmed PMID: 15673139.

[18]. Felicita AS. Orthodontic management of a dilacerated central incisor and partially impacted canine with unilateral extraction - A case report. Saudi Dent J. 2017 Oct;29(4):185-193.Pubmed PMID: 29033530.

[19]. Dinesh SP, Arun AV, Sundari KK, Samantha C, Ambika K. An indigenously designed apparatus for measuring orthodontic force. J Clin Diagn Res. 2013 Nov;7(11):2623-6. doi: 10.7860/JCDR/2013/7143.3631.Pubmed PMID: 24392423.

[20]. Felicita AS. Orthodontic extrusion of Ellis Class VIII fracture of maxillary lateral incisor - The sling shot method. Saudi Dent J. 2018 Jul;30(3):265269.Pubmed PMID: 29942113.

[21]. Carvalho Ferreira FP, Barbosa Lima AP, de Paula EC, Ferreira Conti AC, Valarelli DP, de Almeida-Pedrin RR. Orthodontic Protocol Using Mini-Implant for Class II Treatment in Patient with Special Needs. Case Rep Dent. 2016;2016:1057263.Pubmed PMID: 27847652.

[22]. Sivamurthy G, Sundari S. Stress distribution patterns at mini-implant site during retraction and intrusion--a three-dimensional finite element study. Prog Orthod. 2016;17:4.Pubmed PMID: 26780464.

[23]. Vikram NR, Prabhakar R, Kumar SA, Karthikeyan MK, Saravanan R. Ball Headed Mini Implant. J Clin Diagn Res. 2017 Jan;11(1):ZL02-3.

[24]. Farret MM, Benitez Farret MM. Skeletal class III malocclusion treated using a non-surgical approach supplemented with mini-implants: a case report. J Orthod. 2013 Sep;40(3):256-63.Pubmed PMID: 24009326.

[25]. Felicita AS. Quantification of intrusive/retraction force and moment generated during en-masse retraction of maxillary anterior teeth using mini-implants: A conceptual approach. Dental Press J Orthod. 2017 SepOct;22(5):47-55.Pubmed PMID: 29160344.

[26]. Jain RK, Kumar SP, Manjula WS. Comparison of intrusion effects on maxillary incisors among mini implant anchorage, $j$-hook headgear and utility arch. J Clin Diagn Res. 2014 Jul;8(7):ZC21-4.Pubmed PMID: 25177631.

[27]. Trehan M, Chugh VK, Sharma S. Prevalence of malocclusion in jaipur, India. Int J Clin Pediatr Dent. 2009 Jan;2(1):23-5.Pubmed PMID: 25206094.

[28]. Das UM, Venkatsubramanian, Reddy D. Prevalence of malocclusion among school children in bangalore, India. Int J Clin Pediatr Dent. 2008 Sep;1(1):10-2.Pubmed PMID: 25206082

[29]. Alhammadi MS, Halboub E, Fayed MS, Labib A, El-Saaidi C. Global distribution of malocclusion traits: A systematic review. Dental Press J Orthod. 2018 Nov-Dec;23(6):40.e1-40.e10. doi: 10.1590/2177-6709.23.6.40.e110.onl. Erratum in: Dental Press J Orthod. 2019 Aug 01;24(3):113.Pubmed PMID: 30672991.

[30]. Muwazi LM, Rwenyonyi CM, Tirwomwe FJ, Ssali C, Kasangaki A, Nkamba ME, et al. Prevalence of oral diseases/conditions in Uganda. Afr Health Sci. 2005;5(3):227-33

[31]. Borzabadi-Farahani A, Borzabadi-Farahani A, Eslamipour F. Malocclusion and occlusal traits in an urban Iranian population. An epidemiological study of 11-to 14-year-old children. Eur. J. Orthod. 2009 Oct 1;31(5):477-84.

[32]. Fernandez CCA, Pereira CVCA, Luiz RR, Vieira AR, De Castro Costa M. Dental anomalies in different growth and skeletal malocclusion patterns. Angle Orthod. 2018 Mar;88(2):195-201.Pubmed PMID: 29215300.

[33]. Uslu O, Akcam MO, Evirgen S, Cebeci I. Prevalence of dental anomalies in various malocclusions. Am J Orthod Dentofacial Orthop. 2009 Mar $1 ; 135(3): 328-35$.

[34]. Küchler EC, Risso PA, Costa Mde C, Modesto A, Vieira AR. Studies of dental anomalies in a large group of school children. Arch Oral Biol. 2008 Oct;53(10):941-6.Pubmed PMID: 18490001.

[35]. NADIM KA, RIZWAN S. Prevalence of angles malocclusion according to age groups and gender. Pak Oral Dental J. 2014 Jun 1;34(2). 